\title{
Efficiency of aluminum and iron electrodes in removal of colour, turbidity and total suspended solid from biologically treated municipal wastewater
}

\author{
Arun Kumar Sharma* and A.K. Chopra \\ Department of Zoology and Environmental Sciences, Gurukula Kangri University, Haridwar - 249404 (Uttarakhand), \\ INDIA \\ *Corresponding author. E-mail: asharma.env@gmail.com \\ Received: June 5, 2015; Revised received: August 6, 2015; Accepted: October 8, 2015
}

\begin{abstract}
The present investigation was undertaken to observe the effect of different combinations of almunium and iron (Al-Al, Al-Fe, Fe-Fe and Fe-Al) electrodes on the removal of colour, turbidity (TD) and total suspended solids (TSS) of biologically treated municipal wastewater ( BTMW) using applied potential (V), operating time (OT) and initial $\mathrm{pH}$. The maximum removal of colour $(98.7 \%)$ and TSS $(96.89 \%)$ was found with the use of Al-Al combination with optimum operating conditions (Voltage: $40 \mathrm{~V}$; OT: 40 mins.; IED: $1.0 \mathrm{~cm}$; EA: $160 \mathrm{~cm}^{2}$; initial pH: 7.5 and ST: 30 mins). It was interesting to note that TD of BTMW was completely removed at these optimal operating conditions. The economic evaluation of electrode combinations was observed to be in the order of Fe-Al $\left(1.17 \mathrm{US} \$ / \mathrm{m}^{3}\right)>\mathrm{Al}-\mathrm{Fe}$ (1.11 US $\left.\$ / \mathrm{m}^{3}\right)>\mathrm{Fe}-\mathrm{Fe}\left(1.08\right.$ US $\left.\$ / \mathrm{m}^{3}\right)>\mathrm{Al}-\mathrm{Al}\left(1.01 \mathrm{US} \$ / \mathrm{m}^{3}\right)$ in terms of energy and electrode consumption. Thus, the BTMW can be effectively treated with the Al-Al electrode combination in comparison to other electrode combinations (Al-Fe, Fe-Fe and Fe-Al).
\end{abstract}

Keywords: Aluminium and iron electrodes, Economic evaluation, Turbidity, Total suspended solids, Voltage

\section{INTRODUCTION}

The increase in water demand due to the continuous growth of human population has aroused a strong interest in wastewater recycling which may be reused as a substitute for agricultural irrigation, industrial applications, ground water recharge, contributing to water conservation, municipal water supply and offering good economic benefits (Marchioretto and Reali, 2001). Water reclamation, recycling, and reuse address these challenges by resolving water resource issue to a certain extent by increased public acceptance and improved understanding on public health risks (Tyagi et al., 2011).

The development of new or improved industrial processes that have no or little effect on the nature and processes for the treatment of inevitable wastes. The tendency of the cost of water to increase and the higher cost of effluent treatment due to the new restrictions on its discharge to the environment have induced industries to adopt the programmes aiming at the minimization of water consumption and favoring the development of new methodologies for the optimization of these resources (Souza et al., 2006). The electrolytic process involves the generation of coagulants in situ by electrolytic oxidation of the sacrificial electrode material. Aluminum or iron is usually used as electrodes and their cations are generated by the dissolution of sacrificial anodes upon the application of direct current. The solubility of the metal hydroxide complexes formed depends on $\mathrm{pH}$ and ionic strength. Insoluble flocs are generated in a $\mathrm{pH}$ range between 6.0 and 7.0 as seen from the solubility diagrams of aluminum hydroxide at various $\mathrm{pH}$ values (Bensadok et al., 2008). Grey wastewater has been recognized as one of the wastewater which includes water from baths, showers, hand basins, washing machines, dishwashers, kitchen sinks and constitutes $50-80 \%$ of the total household wastewater but excluding water from the toilet. The discharges of untreated grey wastewater in the ecosystem have substantial impacts on the environment and human health. However, at small scale the heavily polluted sources such as washing machines, dishwashers and kitchen sinks tend to be excluded, whereas at larger scale all sources are used to maximize water savings (Eriksson et al., 2003 and Pidou et al., 2008).

Now a days, Electrolytic wastewater treatment is the need of the hour due to its high effectiveness, its lower maintenance cost, less need for labor, versatility, energy efficiency, safety, selectivity and amenability to automation and cost effectiveness. In this process, the sacrificial metal anode and cathode produce electrically active coagulants along with tiny bubbles of hydrogen and oxygen in water (Chopra et al., 2011). The iron $(\mathrm{Fe})$ and aluminum ( $\mathrm{Al})$ electrodes are consumed and the coagulant is generated and precipitated. There is no requirement of liquid chemical. The $\mathrm{pH}$ adjustment is not needed because electro coagulation (EC) systems typically use metal $\mathrm{Fe}$ or $\mathrm{Al}$ anodes rather than corrosive Fe or Al salt solution (Kobya et al., 2011). 
The electrolytic process can be a candidate for the small-scale wastewater treatment because it is characterized by effective removal of pollutants by strong oxidation, easy operation by a lay person with simple education, no limitation by seasonal variation, variable capability to variable influent flux and quality, rapid treatment, and mobile installation (Hong et al., 2013). The efficiency of EC is influenced by wastewater type, $\mathrm{pH}$, current density, type of metal electrodes used (aluminum, steel, iron), number of electrodes, size of elec-trodes, and configuration of metals (Hossain et al., 2013).

The present study was undertaken to study the efficiency of aluminum (Al) and iron (Fe) electrode combinations in removing colour, turbidity (TD) and total suspended solids (TSS) from biologically treated municipal wastewater (BTMW) at different operating conditions such as applied potential, operating time, electrode area and $\mathrm{pH}$.

\section{MATERIALS AND METHODS}

Collection of wastewater samples: The samples of BTMW were collected from the outlet of activated sludge process (ASP) of the sewage treatment plant (STP), Jagjeetpur, Haridwar (Uttarakhand), India and brought to the laboratory and then used for electrochemical treatment (ET) using different combinations of $\mathrm{Al}$ and $\mathrm{Fe}$ electrodes. The $\mathrm{pH}$ of BTMW was adjusted before the ET process and was maintained by adding the required amount of $\mathrm{H}_{2} \mathrm{SO}_{4}(1 \mathrm{M})$ or $\mathrm{NaOH}(1 \mathrm{M})$.

Electrolytic experimental set up: A rectangular Reactor with external dimensions of height $-30 \mathrm{~cm}$, width $-7 \mathrm{~cm}$, length $-11 \mathrm{~cm}$ and wall thickness $-10 \mathrm{~mm}$ constructed with glass with a capacity of 2.0 liters sample was used for the treatment of BTMW. Different electrode combinations (Al-Al, Al-Fe, Fe-Fe and Fe-Al) were connected to their respective anode and cathode leading to the D.C. power supply (LMC electronics, India $0-500 \mathrm{~V}$ and $0-2 \mathrm{~A}$ ). The different voltages (5 to 40 volts) were passed for different operating times (10 $80 \mathrm{~min}$ ). After ET process, the treated sample was taken for the 30 mins settling time All the experiments were performed at room temperature $\left(30 \pm 2^{\circ} \mathrm{C}\right)$ and at a constant stirring speed $(100 \mathrm{rpm})$ to maintain the uniform mixing of BTMW during the ET. Before conducting an experiment, the electrodes were washed with water, dipped into diluted $\mathrm{HCl}(5 \% \mathrm{v} / \mathrm{v})$ for 5 mins, thoroughly washed with water and then finally

Table 1. Characteristics of BTMW.

\begin{tabular}{ll}
\hline Parameters & $\begin{array}{l}\text { BTMW } \\
\text { (Mean } \pm \text { SD) }\end{array}$ \\
\hline Temperature $\left({ }^{\circ} \mathrm{C}\right)$ & $25.55 \pm 6.67$ \\
$\mathrm{pH}$ & $7.4 \pm 0.52$ \\
Colour $(\mathrm{PCU})$ & $87.94 \pm 24.86$ \\
Turbidity $(\mathrm{NTU})$ & $18.7 \pm 9.7$ \\
EC $(\mu$ siemen $/ \mathrm{cm})$ & $735 \pm 58.08$ \\
TSS $(\mathrm{mg} / \mathrm{l})$ & $115.2 \pm 35.96$ \\
\hline
\end{tabular}

rinsed twice with distilled water as stated earlier (Chopra and Sharma., 2012).

Analytical methods: The colour, TD and TSS of BTMW were analyzed before and after the ET following the standard methods for examination of water and wastewater APHA, 2005. The calculation of colour, TD and TSS of removal efficiencies were carried out using the formula as described earlier (Chopra and Sharma, 2013).

\section{RESULTS AND DISCUSSION}

The characteristics of BTMW before electrochemical treatment are shown in Table 1. The colour, TD and TSS removal from BTMW using different electrode combinations (Al-Al, Al-Fe, Fe-Fe and Fe-Al ) in ET process at different operating conditions such as applied potential (V), operating time (OT), and electrode area (EA) and initial pH are indicated in Figs. 1- 4.

Effect of applied potential (V): As illustrated in Figs. 1 , the experiments on different voltages in the range of 5-40 $\mathrm{V}$ using different combinations of $\mathrm{Al}$ and $\mathrm{Fe}$ electrodes (Al-Al, Al-Fe, Fe-Fe and $\mathrm{Fe}-\mathrm{Al}$ ) showed the increase in removal efficiency of colour, TD and TSS progressively with an increase in the voltages from 5
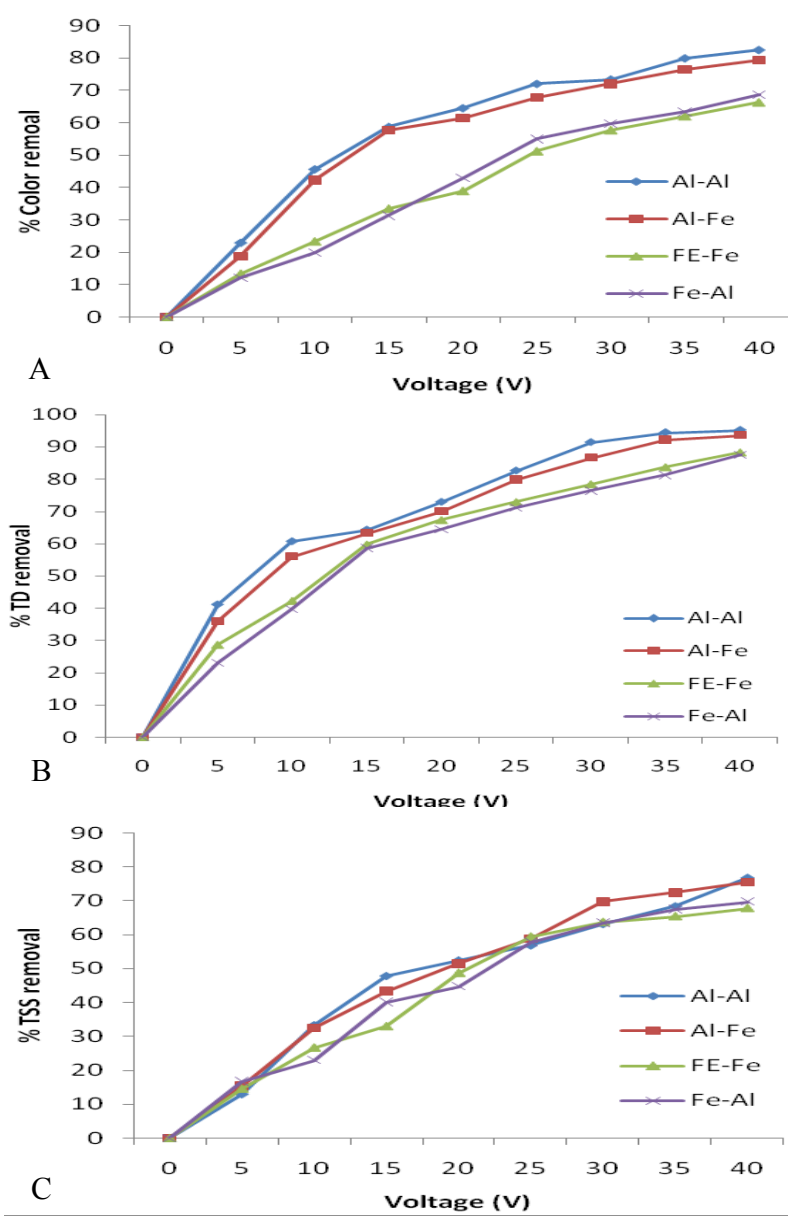

Fig 1. Removal efficiency of (A) colour, (B) TD and (C) TSS using $\mathrm{Al}-\mathrm{Al}, \mathrm{Al}-\mathrm{Fe}, \mathrm{Fe}-\mathrm{Fe}$ and $\mathrm{Fe}-\mathrm{Al}$ electrode combinations with different voltages at constant operating conditions (OT: 30 mins., EA: $80 \mathrm{~cm}^{2}, \mathrm{pH}: 7.5$, ST:30 min.). 
to $40 \mathrm{~V}$ corresponding to the different current densities for different electrode combinations. With Al-Al combination, the maximum removal of colour $(82.54 \%)$ TD $(95.15 \%)$ and TSS $(76.76 \%)$ was observed using the CD $1.67 \mathrm{~A} / \mathrm{m}^{2}$, while with the use of $\mathrm{Fe}-\mathrm{Al}$, there was least removal of colour (68.7\%), TD (87.6\%) and TSS $(69.7 \%)$ using the CD $1.81 \mathrm{~A} / \mathrm{m}^{2}$ and with the operating conditions of OT (30 mins), inter electrode distance (IED) $(1.0 \mathrm{~cm})$, EA $\left(80 \mathrm{~cm}^{2}\right), \mathrm{pH}(7.5)$ and settling time (ST) (30 min.) (Fig.1). Thus, Al-Al electrode combination was the most efficient in comparison to $\mathrm{Al}-\mathrm{Fe}, \mathrm{Fe}-\mathrm{Fe}$ and $\mathrm{Fe}-\mathrm{Al}$ electrode combinations in terms of removal efficiency of colour, TD and TSS. The difference in removal efficiency of the electrodes for these parameters can probably be attributed to the different types of coagulants generated from their respective electrode combinations.

The voltage to the EC system determines the amount of $\mathrm{Al}^{3+}$ ion released from the respective electrodes and the quantity of resulting coagulants. Thus, more $\mathrm{Al}^{3+}$ ions get dissolved into the solution and the formation rate of $\mathrm{Al}(\mathrm{OH})_{3}$ is increased. Also, it is well known that electrical potential not only determines the coagulant dosage rate but also the bubble production rate, size and the flocs growth, which can influence the treatment efficiency of the EC. At higher currents, the supply of metal ions is generated rapidly as compared to the coagulation process, resulting in a decrease of removal efficiency calculated on an equivalent $\mathrm{Al}$ or Fe basis ( Letterman et al., 1999 and Holt et al., 2002). The rate of bubble-generation increases and the bubble size decreases with an increase in CD. Both of these trends are beneficial in terms of high pollutant removal efficiency by $\mathrm{H}_{2}$ floatation (Song et al., 2008). Cho et al. (2010) observed that the colour removal of swine wastewater was very low $(1 \%)$ at $3 \mathrm{~V}$. Further, with an increase in the electric voltage, the colour removal was considerably enhanced, being approximately $67 \%$ and $92 \%$ at 5 and $7 \mathrm{~V}$ respectively. According to Chopra and Sharma (2015), the cell voltage increases gradually with the increase in current density as can be expected from the rate of anodic oxidation resulting in a greater amount of coagulant being formed during the electrolytic treatment that increases the removal of pollutants from wastewater. There was a slight increase in the temperature with the increase in current density because of poor conductivity of the solution.

Effect of operating time (OT): OT also influences the treatment efficiency of the ET. In the present study, the removal of colour, TD and TSS was increased progressively with an increase in the OT from 5 to $40 \mathrm{mins}$ as indicated in the Fig. 2. It was found that the removal efficiency of colour, TD and TSS increased rapidly in the first 20 mins of the ET. For Al-Al, the maximum removal of colour $(86.4 \%)$ TD $(98.20 \%)$ and TSS $(86.4 \%)$ was observed, while with the use of $\mathrm{Fe}-\mathrm{Al}$, there was less removal of colour $(74.5 \%)$ TD $(89.7 \%)$ and TSS $(74.5 \%)$ at 40 mins of OT, beyond which there was no significant removal with the operating
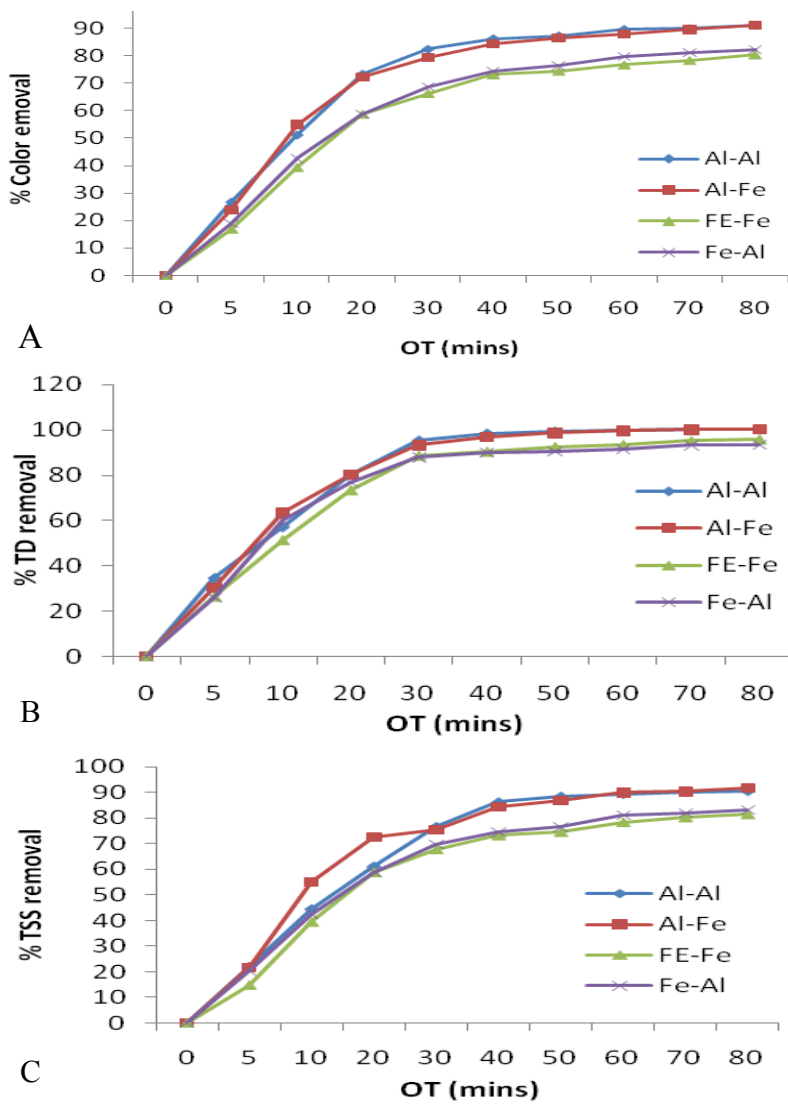

Fig 2. Removal efficiency of (A) colour, (B) TD and (C) TSS using $\mathrm{Al}-\mathrm{Al}, \mathrm{Al}-\mathrm{Fe}, \mathrm{Fe}-\mathrm{Fe}$ and $\mathrm{Fe}-\mathrm{Al}$ electrode combination with different operating time (OT) at constant operating conditions (Voltage: $40 \mathrm{~V}$., EA: $80 \mathrm{~cm}^{2}, \mathrm{pH}: 7.5, \mathrm{ST}: 30 \mathrm{~min}$.).

conditions of voltage: V 40, IED $1.0 \mathrm{~cm}$, EA $80 \mathrm{~cm}^{2}$, pH 7.5 and ST $30 \mathrm{~min}$. This may be due to the fact that the dissolved metal ions and their hydroxides in the BTMW achieved the saturation stage for floc formation. Tir and Mostefa (2008) observed that energy and electrode consumption increase with increase in reaction time thereby showing that reaction time is a very important parameter affecting the cost effectiveness of EC process in polluted waters. Bukhari (2008) stated that $0.05 \mathrm{~A}$ and $0.1 \mathrm{~A}$ of current applied for 5 mins of electrolytic time resulted in $40-50 \%$ and $50-$ $60 \%$ of suspended solids removal efficiency respectively and that the removal efficiency was obtained in proportion to the amount of dissolved materials against each of the working times ranging between 10 and 50 mins. It was also observed by Sharma and Chopra (2013) that the anodic electrode dissolution leads to the release of $\mathrm{Al}$ and $\mathrm{Fe}$ ions and $\mathrm{OH}^{-}$from the cathode leading to the formation of hydroxides of the $\mathrm{Al}$ and $\mathrm{Fe}$ and related oxidized products into the BTMW.

Effect of electrode area (EA): The greater electrode area increased the rate of flock's formation that resulted in an increase in the removal percentage of color, TD and TSS of BTMW. With an increase in EA from 80 to $160 \mathrm{~cm}^{2}$, the maximum removal of colour $(98.7 \%)$ and TSS $(96.89 \%)$ was observed at $160 \mathrm{~cm}^{2}$ 


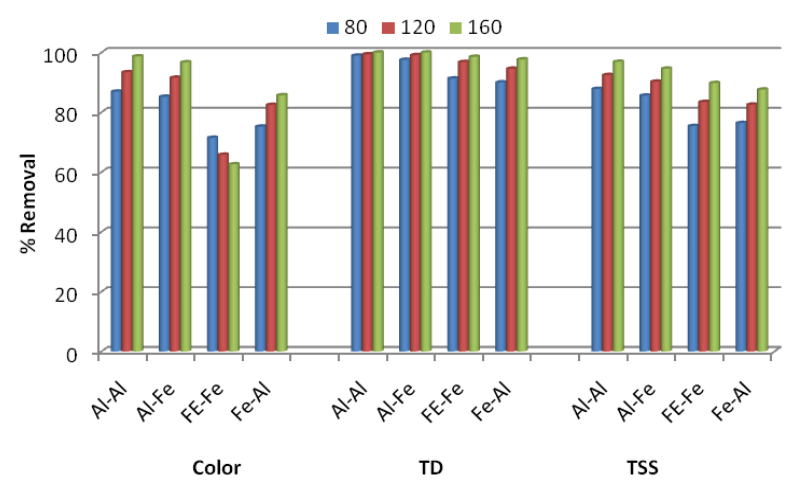

Fig 3. Removal efficiency of color, TD and TSS using Al-Al, $\mathrm{Al}-\mathrm{Fe}, \mathrm{Fe}-\mathrm{Fe}$ and $\mathrm{Fe}-\mathrm{Al}$ electrode combination with different electrode area (EA) at constant operating conditions. (Voltage: $40 \mathrm{~V}$, OT: 40 mins, $\mathrm{pH}: 7.5, \mathrm{ST}: 30 \mathrm{~min}$.).

EA with the use of $\mathrm{Al}-\mathrm{Al}$, while with the use of $\mathrm{Fe}-\mathrm{Al}$, there was least removal of colour (85.69\%) TD $(97.68 \%)$ and TSS $(87.6 \%)$ at $160 \mathrm{~cm}^{2}$ EA. The complete removal of TD was found at the $160 \mathrm{~cm}^{2}$ for Al-Al. The color of BTMW was decreased gradually with an increase of the electrode area of $\mathrm{Fe}-\mathrm{Fe}$ (Fig 3). The increase in EA results in an increase in the bubble generation which in turn increases the removal efficiency of these parameters in BTMW by coagulation and floatation. The removal efficiency can be attributed to a more EA that produced larger amount of anions and cations from the anode and cathode surface.

Daneshava et al., (2005) reported that an increase of electrode area causes a corresponding increase of coagulants. The entire effectiveness of the coagulation process depends on the appropriate amount of coagulant. Escobara et al. (2006) have also observed logistical relationship between electrode geometric area (AG) and copper removal efficiency; and accomplished that an increase in copper removal was related to an increase in $A G$, reaching an optimal value of $35 \mathrm{~cm}^{2}$, with an asymptotic value of near $80 \%$. Chopra and Sharma (2013) observed that with a fourfold increase in the electrode area of $\mathrm{Al}-\mathrm{Fe}$ i.e. from 40 to $160 \mathrm{~cm}^{2}$, the current increased from 0.24 to $0.58 \mathrm{~A}$, which resulted in an increase in the removal percentage of TD, COD and BOD from secondarily treated sewage.

Effect of pH: The efficiency of electrode combinations for the removal of colour, TD and TSS at different $\mathrm{pH}$ values of 5 to 8.5 of BTMW with the operating conditions of voltage: V 40, IED $1.0 \mathrm{~cm}$, EA $160 \mathrm{~cm}^{2}$ and ST 30 min. is shown in Fig. 4. For Al-Al, the maximum removal of colour (98.7\%), TD (100\%) and TSS $(96.89 \%)$ was found at the $\mathrm{pH}$ value of 7.5 , whereas the use of $\mathrm{Fe}-\mathrm{Al}$, there was least removal of colour $(85.69 \%)$, TD $(97.68 \%)$ and TSS $(87.6 \%)$ at the $\mathrm{pH}$ of 7.5 with the constant operating conditions. After that, the removal efficiency of these parameters decreased gradually with the increase in $\mathrm{pH}$ of more than 7.5 at constant operating conditions.

The $\mathrm{pH}$ of electrolyte medium is an important contrib- uting parameter that can influence the electrolytic process. Bayramoglu (2004) indicated that the EC process exhibits some buffering capacity, especially in alkaline medium, which prevents large changes in $\mathrm{pH}$ and shows a decrease of the pollutant removal efficiency. Essadki et al. (2008) observed that the difference between maximum $\mathrm{pH}$ for COD and turbidity can be attributed to the formation of more stable flocs when $\mathrm{pH}$ is about 7, although it does not correspond to the optimum for dye removal. This behavior was attributed to the amphoteric character of aluminum hydroxide which does not precipitate at very low $\mathrm{pH}$ (Adhoum and Monser, 2004). The defluoridation by electrodes is a major contributor to overall removal efficiency in an EC system. Higher removal efficiency of electrodes was corresponding to the influent $\mathrm{pH}$ range of 6.0-7.0, but the efficiency would decrease as the influent becoming acidic or basic. However, the removal efficiency of electrodes would become dominant even under basic conditions $(\mathrm{pH} \geq 7.5)$ ( $\mathrm{Zhu}$ et al., 2007). Therefore, further increase of the influent $\mathrm{pH}$ would decrease the phenol, color and COD removal efficiency of paper mill wastewater (Katal and

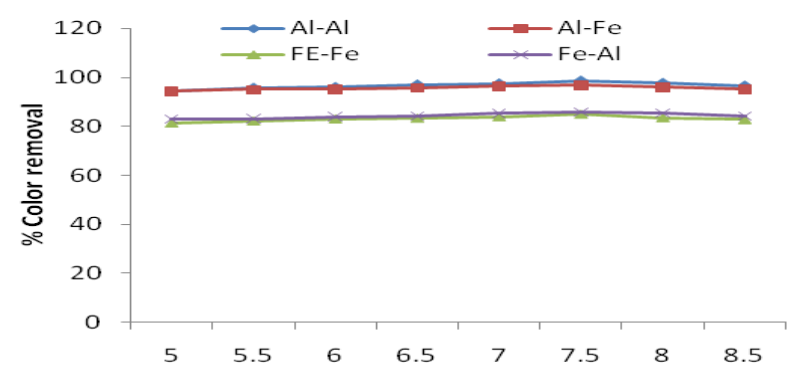

A

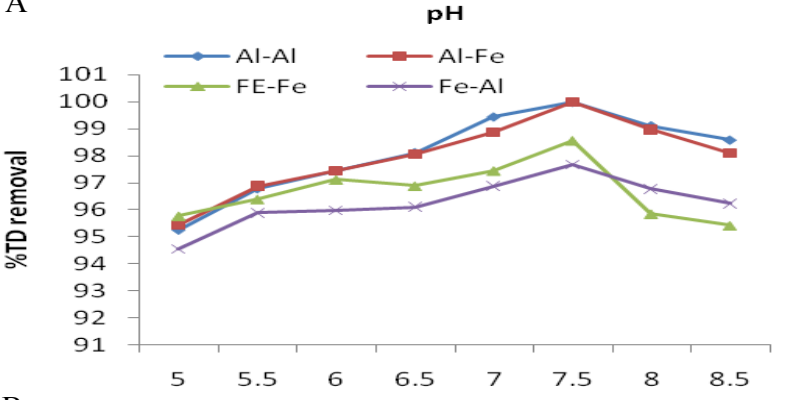

B

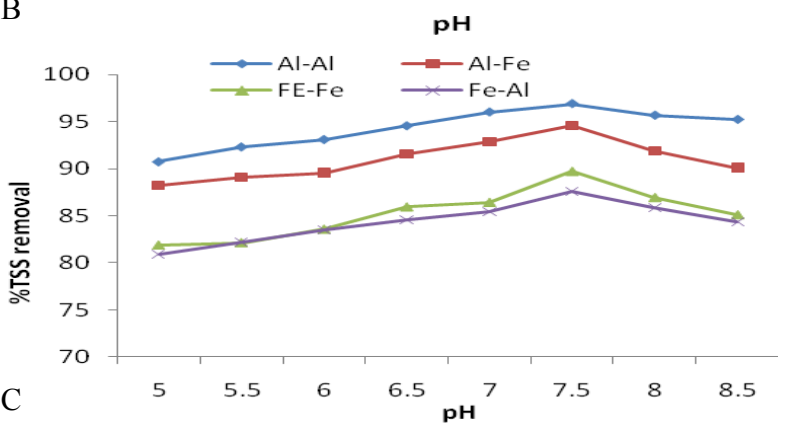

Fig 4. Removal efficiency (A) colour, (B) TD and (C) TSS using $\mathrm{Al}-\mathrm{Al}, \mathrm{Al}-\mathrm{Fe}, \mathrm{Fe}-\mathrm{Fe}$ and $\mathrm{Fe}-\mathrm{Al}$ electrode combinations with different initial $\mathrm{pH}$ at constant operating conditions. (Voltage: $40 \mathrm{~V}$, OT: $40 \mathrm{mins}$; EA: $160 \mathrm{~cm} 2$, ST: $30 \mathrm{~min}$.). 
Pahlavanzadeh, 2011)

Kinetic evaluation: The kinetic study for the rate of removal of colour, TD and TSS were calculated by following the first-order mechanism (El-Ashtoukhy ESZ, Amin 2010). The increase in the voltages from 5 to $40 \mathrm{~V}$ increased the rate constant from 0.0020 to $0.0217 \mathrm{~min}^{-1}$ for Colour , 0.0048 to $0.0436 \mathrm{~min}^{-1}$ for TD and 0.0016 to $0.0219 \mathrm{~min}^{-1}$ for TSS using Al-Al, $\mathrm{Al}-\mathrm{Fe}, \mathrm{Fe}-\mathrm{Fe}$ and $\mathrm{Fe}-\mathrm{Al}$ electrode combinations. The increase in the rate constant may be ascribed to the decrease of colour, TD and TSS of the BTMW using $\mathrm{Al}-\mathrm{Al}, \mathrm{Al}-\mathrm{Fe}, \mathrm{Fe}-\mathrm{Fe}$ and $\mathrm{Fe}-\mathrm{Al}$ combinations. The pseudo first order kinetic exhibited with the significant correlation coefficients $(>.90)$ at maximum voltage of $40 \mathrm{~V}$ (Table 2).

Economic evaluation: Economic evaluation is one of the most important constraints of the ET because it affects the application of any wastewater treatment process. In ET process, the operating cost includes material mainly electrodes and electrical energy cost as well as labour, maintenance, sludge dewatering and its disposal. The operating cost (US $\$ / \mathrm{m}^{3}$ ) was calculated in terms of energy and electrode material cost (Ghosh et al., 2008). In the present study, for all the electrode

Table 2. Rate constant $\left(\mathrm{k}\left(\mathrm{min}^{-1}\right)\right.$ values at variable voltages and their correlation coefficients $\left(\mathrm{r}^{2}\right)$ using $\mathrm{Al}-\mathrm{Al}, \mathrm{Al}-\mathrm{Fe}, \mathrm{Fe}-\mathrm{Fe}$ and $\mathrm{Fe}-\mathrm{Al}$ electrode combination.

\begin{tabular}{|c|c|c|c|c|c|c|c|c|c|}
\hline & & \multicolumn{8}{|c|}{ Al-Al electrode combination } \\
\hline & & 5 & 10 & 15 & 20 & 25 & 30 & 35 & 40 \\
\hline \multirow{2}{*}{ Color } & $\mathrm{K}\left(\min ^{-1}\right)$ & 0.0045 & 0.0083 & 0.0120 & 0.0135 & 0.0157 & 0.0174 & 0.0203 & 0.0217 \\
\hline & $\mathrm{R}^{2}$ & 0.9860 & 0.9952 & 0.9959 & 0.9899 & 0.9832 & 0.9785 & 0.9849 & 0.9848 \\
\hline \multirow[t]{2}{*}{$\mathrm{TD}$} & $\mathrm{K}\left(\min ^{-1}\right)$ & 0.0064 & 0.0116 & 0.0123 & 0.0159 & 0.0224 & 0.0296 & 0.0403 & 0.0436 \\
\hline & $\mathrm{R}^{2}$ & 0.9762 & 0.9905 & 0.9907 & 0.9911 & 0.9916 & 0.9829 & 0.9848 & 0.9949 \\
\hline \multirow[t]{2}{*}{ TSS } & $\mathrm{K}\left(\min ^{-1}\right)$ & 0.0018 & 0.0053 & 0.0080 & 0.0094 & 0.0103 & 0.0130 & 0.0148 & 0.0217 \\
\hline & $\mathrm{R}^{2}$ & 0.9057 & 0.9933 & 0.9903 & 0.9850 & 0.9770 & 0.9919 & 0.9898 & 0.9981 \\
\hline \multicolumn{10}{|c|}{ Al-Fe electrode combination } \\
\hline \multirow[t]{2}{*}{ Color } & $\mathrm{K}\left(\min ^{-1}\right)$ & 0.0039 & 0.0085 & 0.0103 & 0.0123 & 0.0135 & 0.0153 & 0.0182 & 0.0202 \\
\hline & $\mathrm{R}^{2}$ & 0.9808 & 0.9812 & 0.9883 & 0.9827 & 0.9722 & 0.9664 & 0.9698 & 0.9755 \\
\hline \multirow[t]{2}{*}{ TD } & $\mathrm{K}\left(\min ^{-1}\right)$ & 0.0061 & 0.0099 & 0.0123 & 0.0157 & 0.0193 & 0.0248 & 0.0296 & 0.0370 \\
\hline & $\mathrm{R}^{2}$ & 0.9973 & 0.9913 & 0.9867 & 0.9917 & 0.9889 & 0.9913 & 0.9853 & 0.9967 \\
\hline \multirow[t]{2}{*}{ TSS } & $\mathrm{K}\left(\min ^{-1}\right)$ & 0.0039 & 0.0085 & 0.0103 & 0.0123 & 0.0135 & 0.0153 & 0.0182 & 0.0201 \\
\hline & $\mathrm{R}^{2}$ & 0.9525 & 0.9597 & 0.9877 & 0.9641 & 0.9628 & 0.9665 & 0.9658 & 0.9697 \\
\hline \multicolumn{10}{|c|}{ Fe-Fe electrode combination } \\
\hline \multirow[t]{2}{*}{ Color } & $\mathrm{K}\left(\min ^{-1}\right)$ & 0.0020 & 0.0032 & 0.0044 & 0.0058 & 0.0075 & 0.0091 & 0.0103 & 0.0148 \\
\hline & $\mathrm{R}^{2}$ & 0.9676 & 0.9425 & 0.9274 & 0.9374 & 0.9164 & 0.9312 & 0.9360 & 0.9829 \\
\hline \multirow[t]{2}{*}{ TD } & $\mathrm{K}\left(\min ^{-1}\right)$ & 0.0048 & 0.0085 & 0.0103 & 0.0123 & 0.0135 & 0.0153 & 0.0182 & 0.0252 \\
\hline & $\mathrm{R}^{2}$ & 0.9625 & 0.9858 & 0.9742 & 0.9688 & 0.9437 & 0.9425 & 0.9479 & 0.9880 \\
\hline \multirow[t]{2}{*}{ TSS } & $\mathrm{K}\left(\min ^{-1}\right)$ & 0.0016 & 0.0053 & 0.0080 & 0.0094 & 0.0103 & 0.0130 & 0.0148 & 0.0219 \\
\hline & $\mathrm{R}^{2}$ & 0.9058 & 0.9933 & 0.9903 & 0.9850 & 0.9770 & 0.9919 & 0.9898 & 0.9981 \\
\hline \multicolumn{10}{|c|}{ Fe-Al electrode combination } \\
\hline \multirow[t]{2}{*}{ Color } & $\mathrm{K}\left(\min ^{-1}\right)$ & 0.0039 & 0.0085 & 0.0103 & 0.0123 & 0.0135 & 0.0153 & 0.0182 & 0.0202 \\
\hline & $\mathrm{R}^{2}$ & 0.9089 & 0.8806 & 0.9280 & 0.9231 & 0.9498 & 0.9414 & 0.9351 & 0.9499 \\
\hline \multirow[t]{2}{*}{ TD } & $\mathrm{K}\left(\min ^{-1}\right)$ & 0.0049 & 0.0066 & 0.0117 & 0.0130 & 0.0157 & 0.0172 & 0.0203 & 0.0247 \\
\hline & $\mathrm{R}^{2}$ & 0.9818 & 0.9958 & 0.9962 & 0.9922 & 0.9947 & 0.9896 & 0.9862 & 0.9797 \\
\hline \multirow[t]{2}{*}{ TSS } & $\mathrm{K}\left(\min ^{-1}\right)$ & 0.0024 & 0.0038 & 0.0056 & 0.0068 & 0.0076 & 0.0099 & 0.0124 & 0.0148 \\
\hline & $\mathrm{R}^{2}$ & 0.9536 & 0.9502 & 0.9683 & 0.9687 & 0.9242 & 0.9561 & 0.9759 & 0.9826 \\
\hline
\end{tabular}

Table 3. Economic evaluation of $\mathrm{Al}-\mathrm{Al}, \mathrm{Al}-\mathrm{Fe}, \mathrm{Fe}-\mathrm{Fe}$ and $\mathrm{Fe}-\mathrm{Al}$ electrode combination with different electrode areas at opti-

\begin{tabular}{|c|c|c|c|c|c|}
\hline Electrode combinations & $\begin{array}{c}\mathbf{E A} \\
\left(\mathrm{cm}^{2}\right)\end{array}$ & $\begin{array}{c}\text { CD } \\
\left(\mathbf{A} / \mathbf{m}^{2}\right)\end{array}$ & $\begin{array}{c}\mathbf{C}_{\text {electrode }} \\
\times 10^{-5}\left(\mathrm{~kg} / \mathrm{m}^{3}\right) \\
\end{array}$ & $\begin{array}{c}C_{\text {energy }} \\
\left(\mathbf{k W h} / \mathbf{m}^{3}\right)\end{array}$ & $\begin{array}{c}\text { Total OC (uss. } \\
\mathrm{m}^{3} \text { ) }\end{array}$ \\
\hline \multirow{4}{*}{$\mathrm{Al}-\mathrm{Al}$} & 80 & 1.68 & 14.99 & 64.32 & 0.64 \\
\hline & 120 & 2.09 & 18.68 & 80.16 & 0.80 \\
\hline & 160 & 2.65 & 23.71 & 101.76 & 1.01 \\
\hline & 80 & 1.7 & 15.21 & 65.28 & 0.65 \\
\hline \multirow[t]{3}{*}{$\mathrm{Al}-\mathrm{Fe}$} & 120 & 2.14 & 19.12 & 82.08 & 0.82 \\
\hline & 160 & 2.9 & 25.95 & 111.36 & 1.11 \\
\hline & 80 & 1.8 & 50 & 69.12 & 0.69 \\
\hline \multirow[t]{3}{*}{$\mathrm{Fe}-\mathrm{Fe}$} & 120 & 2.22 & 61.81 & 85.44 & 0.85 \\
\hline & 160 & 2.82 & 78.48 & 108.48 & 1.08 \\
\hline & 80 & 1.81 & 50.35 & 69.6 & 0.69 \\
\hline \multirow[t]{2}{*}{$\mathrm{Fe}-\mathrm{Al}$} & 120 & 2.29 & 63.54 & 87.84 & 0.87 \\
\hline & 160 & 3.06 & 85.07 & 117.6 & 1.17 \\
\hline
\end{tabular}


combinations (Al-Al, Al-Fe, Fe-Fe and $\mathrm{Fe}-\mathrm{Al}$ ), the energy consumption increased from $64.32 \mathrm{kwh} / \mathrm{m}^{3}$ to $117.6 \mathrm{kWh} / \mathrm{m}^{3}$ with an increase in $\mathrm{CD}(1.68$ to 3.06 $\mathrm{A} / \mathrm{m}^{2}$ ) that resulted in the increase of electrode consumption from $14.99 \times 10^{-5}$ to $85.07 \times 10^{-5} \mathrm{~kg} / \mathrm{m}^{3}$ for the removal of colour, TD and TSS from BTMW during ET . The operating cost due to electrical energy consumption as well as an electrode assembly for ET of BTMW of Al-Al (1.01 US $\left.\$ / \mathrm{m}^{3}\right)$ was found to be lower than Fe-Fe (1.08 US $\left.\$ / \mathrm{m}^{3}\right)$, Al-Fe (1.11 US \$/ $\mathrm{m}^{3}$ ), and Fe-Al (1.17 US $\$ / \mathrm{m}^{3}$ ) (Table 3$)$.

\section{Conclusion}

The use of all the combinations of electrodes (Al-Al, $\mathrm{Al}-\mathrm{Fe}, \mathrm{Fe}-\mathrm{Fe}$ and $\mathrm{Fe}-\mathrm{Al}$ ) for the removal of color, TD and TSS of BTMW by ET were found to be dependent on the voltage, OT and initial $\mathrm{pH}$. Among the different electrode combinations, Al-Al combination was found to be most effective in removing colour,TD and TSS removal. It was motivating to note that there was no need for $\mathrm{pH}$ adjustment for the treatment of BTMW. The kinetic rate constants for colour, TD and TSS removal at various voltages indicated that pseudo firstorder kinetic was in good agreement with the significant correlation coefficients $(>.90)$ of the experimental results. The operating cost for the ET of BTMW was found to be in the order of $\mathrm{Fe}-\mathrm{Al}\left(1.17 \mathrm{US} \$ / \mathrm{m}^{3}\right)>\mathrm{Al}$ -Fe $\left(1.11\right.$ US $\left.\$ / \mathrm{m}^{3}\right)>\mathrm{Fe}-\mathrm{Fe}\left(1.08 \mathrm{US} \$ / \mathrm{m}^{3}\right)>\mathrm{Al}-\mathrm{Al}(1.01$ US $\left.\$ / \mathrm{m}^{3}\right)$ in terms of energy and electrode consumption. Thus, ET with Al-Al electrode combination should be ideal for the removal of colour, TD and TSS from $\mathrm{BTMW}$ in comparison to $\mathrm{Al}-\mathrm{Fe}, \mathrm{Fe}-\mathrm{Fe}$ and $\mathrm{Fe}-\mathrm{Al}$ electrode combinations.

\section{ACKNOWLEDGEMENTS}

The University Grant Commission, New Delhi, India is acknowledged for providing the financial support in the form of UGC Research Fellowship (F.4-1/2006 (BSR) 7-70/2007 BSR) to Mr. Arun Kumar Sharma.

\section{REFERENCES}

Adhoum, N. and Monser, L. (2004). Decolourization and removal of phenolic compounds from olive mill wastewater by electro coagulation. Chem. Eng. Process, 43: 1281-1287.

Bayramoglu, M., Kobya M., Can, O.T. and Sozbir, M. (2004). Operating costs analysis of electrocoagulation of textile dye wastewater. Sep Purif Technol., 37:117125

Bensadok K, Benammar S, Lapicque F, Nezzal G (2008). Electrocoagulation of cutting oil emulsions using aluminum plate electrodes. J Hazard Mater., 152(1):423-430

Bukhari, A.A. (2008). Investigation of the electrocoagulation treatment process for the removal of total suspended solids and turbidity from municipal wastewater. Bioresour. Technol., 99:914-921.

Cho, J.H., Lee, J.E., Ra, C.S. (2010).Effects of electric voltage and sodium chloride level on electrolysis of swine wastewater. Journal of Hazardous Materials 180 (2010)
$535-541$

Chopra, A. K. and Sharma, A. K. (2013). Removal of turbidity,COD and BOD from secondarily treated sewage water by electrolytic treatment. Appl. Water Sci., 3:125-132.

Chopra, A. K., Sharma, A. K. and Kumar, V. (2011). Overview of electrolytic treatment: An alternative technology for purification of wastewater, Arch. Appl. Sci. Res. 3(5):191-206.

Chopra, A.K. and Sharma, A.K. (2015) Effect of electrochemical treatment on the COD removal from biologically treated municipal wastewater. Desalin Water Treat., 53(1):41-47

Chopra, A. K. and Sharma, A. K. (2012). Efficiency of turbidity and BOD removal from secondarily treated sewage by electrochemical treatment. Journal of Applied and Natural Science, 4:304-309.

Daneshava, N, Oladegaragoze, A. and Djafarzadeh, N. (2005). Decolorization of basic dye solutions by electrocoagulation: an investigation of the effect of operational parameters. J Hazard Mater., 129:116-122

El-Ashtoukhy ESZ and Amin NK (2010) Removal of acid green dye from wastewater by anodic oxidation and electrocoagulation - a comparative study. J Hazard Mater., 179:113-119

Eriksson E, Auffarth K, Eilersen AM, Henze M, Ledin A (2003). Household chemicals and personal care products as sources for xenobiotic organic compounds in grey wastewater. Water $S A, 29: 135-146$

Escobara, C., Cesar, S.S. and Toral, M. (2006) Optimization of the electrocoagulation process for the removal of copper, lead and cadmium in natural waters and simulated wastewater. J Environ Manag., 81(4):384-391

Essadki A.H., Bennajah, M., Gourich, B., Vial, C., Azzi, N. and Delmas, H. (2008). Electrocoagulation/ electroflotation in an external-loop airlift reactor- Application to the decolorization of textile dye wastewater A case study. Chem. Eng. Process., 47:1211- 1223.

Ghosh, D., Medhi, C.R., Solanki, H., and Purkait, M. K., (2008). Decolorization of Crystal Violet Solution by Electrocoagulation. Journal of environmental protection science, 2:25-35.

Holt P. K., Barton G. W., Wark M., and Mitchell C. A. (2002). A quantitative comparison between chemical dosing and electrocoagulation. Colloids and Surfaces A, 211(2-3): 233-248.

Hong, KiHo, Kim, W.Y., Son D.J., Yun, C.Y., Sun, P.Q. , Chang, D. , Bae H. S. , Kim, J.H. , Sunwoo Y. and Kim, D. G. (2013). Treatment of Weak Sewage by Continuous Electrochemical Process using Noble Metal Electrodes. Int. J. Electrochem. Sci., 8: 12741 - 12756

Hossain, Md. Milon, Mahmud, Md. Iqbal Parvez Md. Shohan, Cho and Haeng Muk (2013). Impact of Current Density, Operating Time and $\mathrm{pH}$ of Textile Wastewater Treatment by Electrocoagulation Process Environ. Eng. Res. 18(3) : 157-161.

Katal R, Pahlavanzadeh H (2011) Influence of different combinations of aluminum and iron electrode on electro coagulation efficiency: Application to the treatment of paper mill wastewater. Desalination 265:199-205

Letterman R. D., Amirtharajah A., and Melia C. R. O., A (1999). Handbook of Community Water Supplies, AWWA, McGraw- Hill, NewYork, NY, USA,.

M. Kobya, U. Gebologlu, F. Ulu, S. Oncel and E. Demirbas, (2011). Removal of arsenic from drinking water by the electrocoagulation using $\mathrm{Fe}$ and $\mathrm{Al}$ electrodes. Electrochimica Acta., 56: 5060-5070 
Marchioretto M.M. and Reali M.A.P.(2001). Ozonation followed by coagulation/flocculation as post-treatment of the effluent from an anaerobic baffled reactor treating domestic sewage, Water Sci. Technol. 43 (8): 99-106.

Pidou M., Avery, L., Stephenson, T., Jeffrey, P., Parsons, S.A., Liu, S., Memon, F. A. and Jefferson, B. (2008). Chemical solutions for greywater recycling. Chemosphere $71: 147-155$

Sharma AK and Chopra AK (2013) Removal of COD and BOD from biologically treated municipal wastewater by electrochemical treatment. J Appl Nat Sci., 5(2):475481

Song, S., Yao, J., He, Z., Qiu, J. and Chen, J. (2008). Effect of operational parameters on the decolorization of C.I. Reactive Blue 19 in aqueous solution by ozone enhanced elec- trocoagulation. J. Hazard. Mater., 152: 204-210.

Souza U. S.M.A Guelli, Melo, A.R. and Ulson de Souza A.A. (2006). Resources Conservation and Recycling, 49:1-13.

Tir M. and Mostefa N. M. (2008).Optimization of oil removal from oily wastewater by electrocoagulation using response surface method, Journal of Hazardous Materials, 158( 1):107-115

Tyagi, V. K., Sahoo, B. K., Khursheed, A., Kazmi, A.A., Ahmad, Z. and Chopra, A.K. (2011). Fate of coliforms and pathogenic parasite in four full-scale sewage treatment systems in India. Environ Monit Assess., 181(1-4):123-35.

Zhu J., Zhao H. and Ni, J. (2007). Fluoride distribution in electrocoagulation defluoridation process, Sep. Purif. Technol. 56 : 184-191. 